\title{
EgG PRoduCtion IN CULEX PIPIENS PALLENS COQUILLETT III. GROWTH AND DEGENERATION OF OVARIAN FOLLICLES
}

\author{
Teruhiko HOSOI
}

The Tokyo Institute of Technology

(Received: October 9th, 1953)

As is well known, the number of eggs produced by a mosquito varies extensively, depending on the kind or amount of the ingested blood. Some important results of the recent investigations on this subject are summarized in the book by Bates (1949). Previous information may be classified in two categories, one of which is dealing with utility of blood or blood fractions on egg development and the other with physiological differences of the mosquitoes, such as autogeny, diapause, gonotrophic dissociation, etc. The two problems are to be intimately related to each other; nevertheless there has been little work made on elucidating, for instance, the diapause state of adult females in terms of metabolic processes in the ovarian follicles.

The attempt, however, will not be easily realized at once, especially with such species as the Japanese Culex pipiens pallens in which no fundamental knowledge of the egg production has yet been obtained. Hence the present work was undertaken, to begin with, for ascertaining the fate of ovarian follicles during the course of their development. Techniques and methods are essentially not different from those described before (Hosoi, 1953). In case statistical treatments are required, the significance of the differences is judged, or the confidence limits of the means are taken, by a $95 \%$ confidence coefficient.

\section{Number of Follicles Developed in Mosquitoes Following}

\section{a Full feeding on Human Blood}

Usually an extensive variation appeared in the number of eggs produced by a female mosquito subsequently to an engorgement of human blood. The capacity for egg formation seemed to depend partly on the size of the mosquito. Since it became necessary on many occasions to estimate the comparative abundance of mature follicles in individuals of different sizes, an attempt was made to find some reasonable standard for these numbers as conveniently utilizable in routine work as possible.

The available data were taken from 73 batches of the mosquitoes, raised under various conditions in all seasons of the years 1948-49. The insects had taken a meal of human blood to repletion. Although the majority of them were dissected after intervals sufficient to allow maturation of the follicles, some were also examined in earlier periods, consequently exhibiting follicles 
of younger stages. Among 2163 individuals, $271(12.5 \%)$ showed gonotrophic dissociation; in other words, all the follicles in them stayed at stage I after the ingested blood had been consumed. The remaining 1892 females were divided into five groups according to their follicle stages, and also into several classes of wing length. A marked uniformity was commonly observed in the stage of all follicles developing in the same individual, except that the ovaries of stage II displayed irregularities, accompanied as well by a considerable number of degenerating follicles.

For all the above considerations, any class of a given group still involved a great range of variation in the number of developed follicles in each mosquito. These variations, however, seemed to show a normal distribution; therefore mean numbers of developed follicles per mosquito of each class and group were calculated, excluding a small number of aberrations (34 females in all), in which an extremely small proportion of follicles was developing (less than 50, 40 and 30 in number, in stages IIa, IIb and III-V, respectively).

The mean number of follicles was found to increase with the wing length of the mosquito and decrease with the stage of the follicles, attaining a stable value at stage III. For a given wing length, groups of the stages III, IV and $\mathrm{V}$ were considered to belong virtually to the same population; accordingly they were included together. These values are shown in Table 1. Among

Table 1. Mean numbers of developed follicles per mosquito of stages III-V

\begin{tabular}{ccc}
\hline $\begin{array}{c}\text { Wing length } \\
\text { in mm }\end{array}$ & $\begin{array}{c}\text { No. of mosq. } \\
\text { measured }\end{array}$ & $\begin{array}{c}\text { No. of developed } \\
\text { follicles per mosq. }\end{array}$ \\
\hline 3.3 & 4 & $45.5 \pm 17.5$ \\
3.5 & 14 & $62.7 \pm 7.9$ \\
3.7 & 22 & $67.4 \pm 6.7$ \\
3.9 & 98 & $86.9 \pm 4.3$ \\
4.1 & 200 & $91.8 \pm 3.6$ \\
4.3 & 270 & $104.1 \pm 3.5$ \\
4.5 & 360 & $112.4 \pm 3.3$ \\
4.7 & 260 & $114.8 \pm 4.7$ \\
4.9 & 182 & $121.8 \pm 5.3$ \\
5.1 & 58 & $123.3 \pm 8.2$ \\
5.3 & 6 & $125.5 \pm 19.8$
\end{tabular}

several equations tentatively applied to express the relation of the mean number of follicles to the wing length, the following has been found to fit any group of the stages III, IV and V fairly well. This is

$$
\mathrm{y}=\mathrm{A}-\frac{\mathrm{B}}{\mathrm{x}^{3}},
$$

were $y$ denotes the number of follicles, $x$ the wing length and $A$ and $B$ the constants. In the united groups of the stages III, IV and V, the figures of 
the constants are 153.6 for $\mathrm{A}$ and 4010 for $\mathrm{B}$, provided one millimetre is taken as the unit of $x$. The theoretical numbers of developed eggs used as the standards in a series of former experiments (Part I and II) have been calculated from this formula. Now, if $\mathrm{x}^{3}$ is taken on the abscissa and $\mathrm{y}$ on the ordinate, a hyperbola will be obtained (Fig. 1, III IV V).

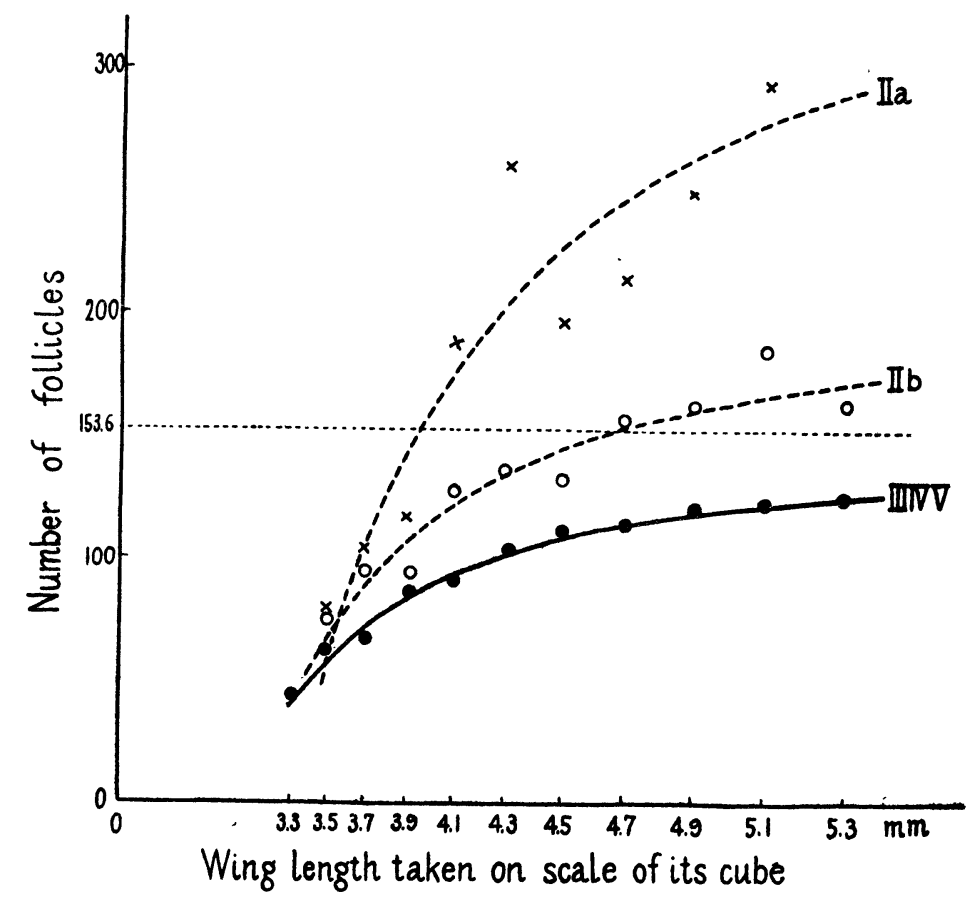

Fig. 1. Relation between wing length and mean number of follicles developed in a blood-fed female.

Curves IIa, IIb and III IV V correspond to the theoretical numbers of follicles in the respective stages. Means of the observed numbers are plotted with inclined crosses, circles and dots.

Similar equations may conveniently be applied to the groups of the stages IIa and IIb, with numerical values for the constants as follows:

$$
\begin{array}{lll}
\text { IIa } & \mathrm{A}=385.2 & \mathrm{~B}=14200 \\
\text { IIb } & \mathrm{A}=215.6 & \mathrm{~B}=6315
\end{array}
$$

The theoretical numbers of developing follicles thus obtained with stages IIa and IIb are also shown in Fig. 1, being represented by the corresponding curves, 


\section{Degeneration of Follicles in the Course of Development}

In mosquitoes the rudimentary ovaries can be detected as early as the larval stage, whereas follicles are formed only after the insects have developed to the pupal stage (Imms, 1907-08). In my experience ovarian follicles in pupae are so small that they can hardly be counted by the dissection. Immediately after emergence, however, the longer diameter of a primary follicle measures about $35 \mu$ and the shorter $30 \mu$, while the longer diameter of a secondary follicle measures $20-25 \mu$. At moderate temperatures the primary follicles attain their maximum size within a few days after emergence, the diameters being $75 \mu$ and $70 \mu$, and remain in this state for an indefinite period until the mosquito takes a blood meal, when the second stage of follicle growth commences. The secondary follicles never reach the second stage unless the mosquito takes another blood meal, usually after laying the first batch of eggs. This forms a marked contrast to the growth of follicles in Anopheline mosquitoes described by Christophers (1936), in which the secondary follicles attain the second stage about the time that the primary follicles complete their development.

Follicles of $C$. pipiens pallens females, on commencing growth of the second stage, sooner or later complete their development and rarely stay long in the intermediate stages. Nicholson (1921) has described degeneration of follicles in his histological studies on the egg formation of Anopheles maculipennis. Such degeneration of follicles is found to be of common occurrence with $C$. pipiens pallens fed on human blood, in case the ovariss of early follicle stages are examined. When a freshly dissected ovary is examined, degenerating follicles can easily be distinguished from normal ones by their structureless appearance as well as by their unusually small size (not larger than the normal stage-II follicles). The phenomenon of follicle degeneration may probably be responsible for the differences in the number of follicles among the mosquitoes of different follicle stages — a fact mentioned in the foregoing section. Hence the following experiments were carried out.

(1) Mosquitoes raised from the same batch of larvae and given a full meal of human blood at the same period were isolated in a cage, from which several females were daily taken out at random for dissection. In Table 2 is

Table 2. Diminution in the number of developing follicles

\begin{tabular}{|c|c|c|c|c|c|c|c|c|}
\hline \multirow{3}{*}{$\begin{array}{l}\text { Days } \\
\text { after } \\
\text { feeding }\end{array}$} & \multirow{3}{*}{$\begin{array}{l}\text { Wing } \\
\text { length } \\
\text { in } \mathrm{mm}\end{array}$} & \multirow{3}{*}{ Stage } & \multirow{3}{*}{$\begin{array}{l}\text { No. of } \\
\text { mosq. }\end{array}$} & \multirow{3}{*}{$\begin{array}{l}\text { Actual no. of } \\
\text { follicles }\end{array}$} & \multicolumn{4}{|c|}{ Relative no. of follicles } \\
\hline & & & & & \multicolumn{2}{|c|}{ II a taken as 1} & \multicolumn{2}{|c|}{ IIb taken as 1} \\
\hline & & & & & A & B & A & B \\
\hline 1 & 4.3 & II a & 7 & $272.6 \pm 21.3$ & 1 & 1 & - & - \\
\hline ? & 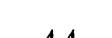 & IIb & 6 & $194.9 \pm 17.8$ & 0.71 & 0.68 & 1 & 1 \\
\hline & & (IIII & 4) & $148.1 \pm 8.8$ & 0.54 & 0.52 & 0.76 & 0.76 \\
\hline 3 & 15 & IV & & & 0.51 & 0,59 & 0.72 & 0.76 \\
\hline 4 & 4.0 & Iv & 5 & $100.0-1100$ & & & & \\
\hline
\end{tabular}

(Note) A: values based on the observed numbers; B: values based on the theoretical numbers. 
shown one of the result of these experiments. Degenerating follicles, although regularly found in the ovaries of stage IIb, have been excluded from counting because of their temporary nature. It is evident from the table that the number of developing follicles actually decreases during the early course of follicle growth. So far as the present material is concerned, the mean numbers of developing follicles invariably surpass the corresponding theoretical numbers (cf. Table 1 and Fig. 1); nevertheless, regarding the ratios of decrease in the course of follicle growth, there are striking equalities between the values based on observation and those based on the theoretical number of follicles.

(2) The second series of experiments was done to confirm whether some follicles degenerate also during the first stage of their development previous to the blood-feeding of the mosquito. Females raised from the same batch of larvae were fed on a solution of cane sugar at a moderate temperature and dissected on different days. Since the lengths of primary follicles at the final dissection were found to be about twice as great as the lengths of follicles at the first dissection, follicle growth undoubtedly took place in this period also. No significant differences, however, were detected in the number of follicles among the mosquitoes of different ages. Consequently, degeneration of follicles, if it exists, is considered to be negligible during the course of the first-stage development.

(3) In the third series of experiments, the ratio of follicle degeneration following a blood meal was measured by the number of first stage follicles produced in the mosquito. The method was similar to that described in the first experiment. As is clearly shown in Table 3, a definite, great percentage

Table 3. Number of developing follicles compared with the number of stage-I follicles

\begin{tabular}{|c|c|c|c|c|c|}
\hline Batch & $\begin{array}{c}\text { No. of } \\
\text { mosq. }\end{array}$ & $\begin{array}{l}\text { Wing } \\
\text { length } \\
\text { in } \mathrm{mm}\end{array}$ & $\begin{array}{c}\text { Follicle } \\
\text { stage }\end{array}$ & $\begin{array}{l}\text { No. of } \\
\text { follicles }\end{array}$ & Ratio \\
\hline \multirow{3}{*}{$\mathbf{L}$} & 24 & 4.50 & I & $293.0 \pm 12.3$ & 1 \\
\hline & 14 & 4.49 & $\mathrm{IIa}$ & $260.4 \pm 13.1$ & 0.889 \\
\hline & 17 & 4.58 & III-V & $123.9 \pm 6.2$ & 0.423 \\
\hline \multirow{2}{*}{$\mathbf{H}\{$} & 24 & 3.57 & I & $198.7 \pm 13.7$ & 1 \\
\hline & 26 & 3.55 & IV-V & $86.5 \pm 7.2$ & 0.435 \\
\hline
\end{tabular}

(Note) Mosquitoes were raised at $10-20^{\circ} \mathrm{C}$ in $\mathrm{L}$ and $26-32^{\circ} \mathrm{C}$ in $\mathrm{H}$.

(indeed more than 50\%) of the existing follicles is prevented from maturation when the mosquito is fed on human blood, mostly because of degeneration, to which actively developing second-stage follicles are likely to be subjected. The ratio of decrease in the number of follicles is remarkably constant irrespective of the difference in the breeding temperature and of the consequent differences in the size of the mosquitoes as well as in the actual number of follicles formed and matured. 


\section{Variation in Egg Formation Depending on the Source OF BLOOD}

It is reported that the number of eggs laid by a mosquito varies, depending on the species of host animal on which the insect has fed, and that human blood furnishes rather poor nourishment for egg production, regardless of the mosquito species (Roy, 1931; Woke, 1937c). This is also confirmed in my study with $C$. pipiens pallens, as will be stated here briefly with special notes on the growth activity of follicles.

In the preliminary experiment, females of the same batch were fed on man, mouse and chicken, resulting in maturation of follicles on an average 112, 224 and 310 in number, respectively. Comparing these numbers with the standard of the corresponding wing length, the average follicle-growth indexes were obtained as 1.02, 0.25 and 2.76. Results with Culex tritaeniorhynchus Giles were quite similar; i. e. matured follicles were 136, 166, 170 and 211 in number respectively, following feeding on the blood of man, mouse, guinea pig and chicken.

The results of further experiments with two batches of $C$. pipiens pallens are summarized in Table 4. The mosquitoes had been bred in October at

Table 4. Difference in the follicle growth between the mosquitoes fed on man and those fed on chicken

\begin{tabular}{|c|c|c|c|c|c|c|c|c|c|c|}
\hline \multirow{2}{*}{ Batch } & \multirow{2}{*}{$\begin{array}{c}\text { Source } \\
\text { of blood }\end{array}$} & \multirow{2}{*}{\begin{tabular}{|c|} 
Days \\
after \\
feeding
\end{tabular}} & \multicolumn{5}{|c|}{$\begin{array}{l}\text { No. of mosquitoes } \\
\text { (Follicle Stage) }\end{array}$} & \multirow{2}{*}{$\begin{array}{l}\text { Wing } \\
\text { length } \\
\text { in mm }\end{array}$} & \multirow{2}{*}{$\begin{array}{l}\text { Mean no. of } \\
\text { follicles } \\
\text { per mosq. }\end{array}$} & \multirow{2}{*}{$\begin{array}{l}\text { Follicle } \\
\text { growth } \\
\text { index }\end{array}$} \\
\hline & & & I & II & $\begin{array}{l}\text { cle } \\
\text { III }\end{array}$ & IV & V & & & \\
\hline \multirow{3}{*}{$\mathrm{k}$} & (Unfed) & - & 7 & 0 & 0 & 0 & 0 & 4.51 & $313.1 \pm 19.8$ & - \\
\hline & Man & 3 & 0 & 0 & 1 & 0 & 7 & 4.59 & $110.5 \pm 19.5$ & 0.98 \\
\hline & Chicken & 3 & 0 & 0 & 0 & 0 & 9 & 4.52 & $233.6 \pm 34.6$ & 2.11 \\
\hline \multirow{3}{*}{$\mathrm{m}$} & (Unfed) & - & 7 & 0 & 0 & 0 & 0 & 4.79 & $383.6 \pm 34.6$ & 一 \\
\hline & Man & 4 & 4 & 2 & 1 & 3 & 0 & 4.75 & $111.5 \pm 16.5^{*}$ & 0.96 \\
\hline & Chicken & 4 & 0 & 0 & 0 & 0 & 7 & 4.76 & $298.9 \pm 26.5$ & 2.54 \\
\hline
\end{tabular}

* Average among mosquitoes with stage-III and -IV follicles.

$16-22^{\circ} \mathrm{C}$ and maintained at $22-30{ }^{\circ} \mathrm{C}$ throughout the experiment. Evidently, chicken's blood is more suitable for egg production than human blood, which is shown in the following three events: (1) more than twice as many follicles matured in the chicken-fed mosquitoes as they did in the human-fed ones; (2) follicle growth took place more rapidly in the chicken-fed mosquitoes; (3) gonotrophic dissociation was observed only among the human-fed mosquitoes.

\section{Variation in Egg Formation Depending on the Amount OF INGESTED BLOOD}

The retarded or decreased egg production, involving gonotrophic dissociation as the extreme case, is also found in mosquitoes which have taken an 
insufficient amount of a blood meal. Here will be reported results of a few experiments carried out in relation to this subject.

(1) Roy (1936) has reported with Aedes aegypti L. that there exists a minimum amount for blood ingestion below which the mosquito is incapable of laying eggs. A brief description was also made previously with Shanghai C. pipiens pallens that a small amount of human blood could not induce development of any follicles to the second stage (Hosoi, 1944). A similar relationship was established again in the present experiment, revealing as well a small number of transitional forms.

Mosquitoes of relatively small size bred at $27-31^{\circ} \mathrm{C}$ were given various amounts of human blood by disturbing the cage frequently during feeding. These females were then divided into four lots according to the amount of ingested blood (based on the apparent distention of the abdomen) and dissected 3 days later, giving results shown in Table 5. It is manifest that an insufficient

Table 5. Follicle growth in mosquitoes after ingesting various amounts of human blood

\begin{tabular}{|c|c|c|c|c|c|c|c|c|c|c|c|}
\hline \multirow{2}{*}{$\begin{array}{c}\text { Amount } \\
\text { of } \\
\text { blood }\end{array}$} & \multirow{2}{*}{$\begin{array}{c}\text { No. of } \\
\text { mosq. } \\
\text { dissected }\end{array}$} & \multicolumn{8}{|c|}{ No. of mosq. according to follicle stage* } & \multirow{2}{*}{$\begin{array}{l}\text { Total } \\
\text { no. of } \\
\text { gravid } \\
\text { mosq. }\end{array}$} & \multirow{2}{*}{$\begin{array}{l}\text { Average** } \\
\text { no. of } \\
\text { developed } \\
\text { follicles }\end{array}$} \\
\hline & & \multicolumn{2}{|c|}{$\mathrm{I}$} & $\begin{array}{c}\text { II } \\
150\end{array}$ & \multicolumn{3}{|c|}{ III } & \multicolumn{2}{|c|}{ IV } & & \\
\hline- & 16 & 14 & 2 & 0 & 0 & 0 & 0 & 0 & 0 & 0 & - \\
\hline, \pm+ & 12 & 10 & 2 & 0 & 0 & 0 & 0 & 0 & 0 & 0 & - \\
\hline++ & 19 & 13 & 3 & 1 & 1 & 1 & 0 & 0 & 0 & 3 & 44.3 \\
\hline+++ & 14 & 1 & $1^{-}$ & 0 & 3 & 2 & 2 & 4 & 1 & 12 & 76.5 \\
\hline
\end{tabular}

* Follicle length in $\mu$.

** Average number per gravid mosquito.

meal brought about reduction both in the number of developing follicles and in the rate of follicle growth. Gonotrophic dissociation occurred in two individuals out of 14 full fed.

(2) Among about 3,000 females dissected for examination of the ovaries following a blood feeding, there were four individuals in which one of the paired ovaries had atrophied so as to contain none or only rudimentary follicles (Table 6, a-d). In order to obtain more data, extirpation of the ovary of one side from normal females was undertaken, ending in failure because of the high mortality. Another attempt was made by blocking the fourth and fifth abdominal spiracles on one side of the insect with machine oil (blocking of those on both sides proved fatal to the insect). Out of 42 females operated on, 23 individuals gorged human blood and 5 lived long enough to be examined (e-i in Table 6). 
Table 6. Growth of follicles in mosquitoes with one of the ovaries impaired

\begin{tabular}{|c|c|c|c|c|}
\hline \multicolumn{3}{|c|}{ Female with a single ovary } & \multicolumn{2}{|c|}{ Control (normal females) } \\
\hline Individual & Follicle stage & No. of follicles & Follicle stage & $\begin{array}{l}\text { Average no. of fol- } \\
\text { licles per mosquito }\end{array}$ \\
\hline a & II & 62 & II & 140 \\
\hline $\mathrm{b}$ & II & 152 & II & 143 \\
\hline c & III, IV & 59 & III-V & 101 \\
\hline $\mathrm{d}$ & $\mathrm{V}$ & 52 & $\mathrm{~V}$ & 82 \\
\hline e & IV & 107 & IV & 109 \\
\hline $\mathrm{f}$ & II & 90 & IV & 109 \\
\hline $\mathbf{g}$ & III, IV & 36 & IV & 84 \\
\hline $\mathbf{h}$ & $\mathrm{V}$ & 106 & $\mathrm{~V}$ & 99 \\
\hline $\mathbf{i}$ & $\mathbf{V}$ & 113 & $\mathbf{V}$ & 99 \\
\hline
\end{tabular}

(Note) Mosquitoes were dissected after various intervals following a full feeding on human blood. a-d: naturally occurring cases; e-i : operated females.

In both series of experiments, the number of developed follicles in the remaining intact ovary is, on rough estimation, either equal to or half the number of those in both ovaries of the control females. It follows that the mosquito is capable of raising a compensatory number of eggs from follicles which would have degenerated if the insect were provided with a greater number of follicles.

(3) When mosquitoes which had fed twice on human blood before oviposition were dissected two or three days after the second meal, they occasionally exhibited the ovaries undergoing two phases of follicle development. The follicles of more advanced development had attained the final stage, while others remained in the second or third stage. These younger follicles could be clearly distinguished from the degenerating forms. Since no other intermediate stages were encountered, the younger follicles can reasonably be considered as those which started growth on the second blood meal. Usually each supplementarily growing follicle was enclosed singly in an ovariole of its own, but at times they also appeared in the ovarioles which were already occupied by the fully developed egg matured after the first meal. When the dissection was performed after a sufficient interval following the second meal, no such two phases of follicle growth were observed, but all the follicles, if they developed at all, had invariably reached their final stage. This fact would indicate that the additional blood feeding could raise a certain number of first-stage follicles to maturity in a later period.

The results of these repeated feedings are summarized in Table 7. More cases of the additional egg formation occurred among the mosquitoes which had formed no eggs ( $a$ and $b$ in Table 7 ) or a smaller number of eggs (the 
Table 7. Number of follicles developed by two consecutive feedings on human blood before oviposition

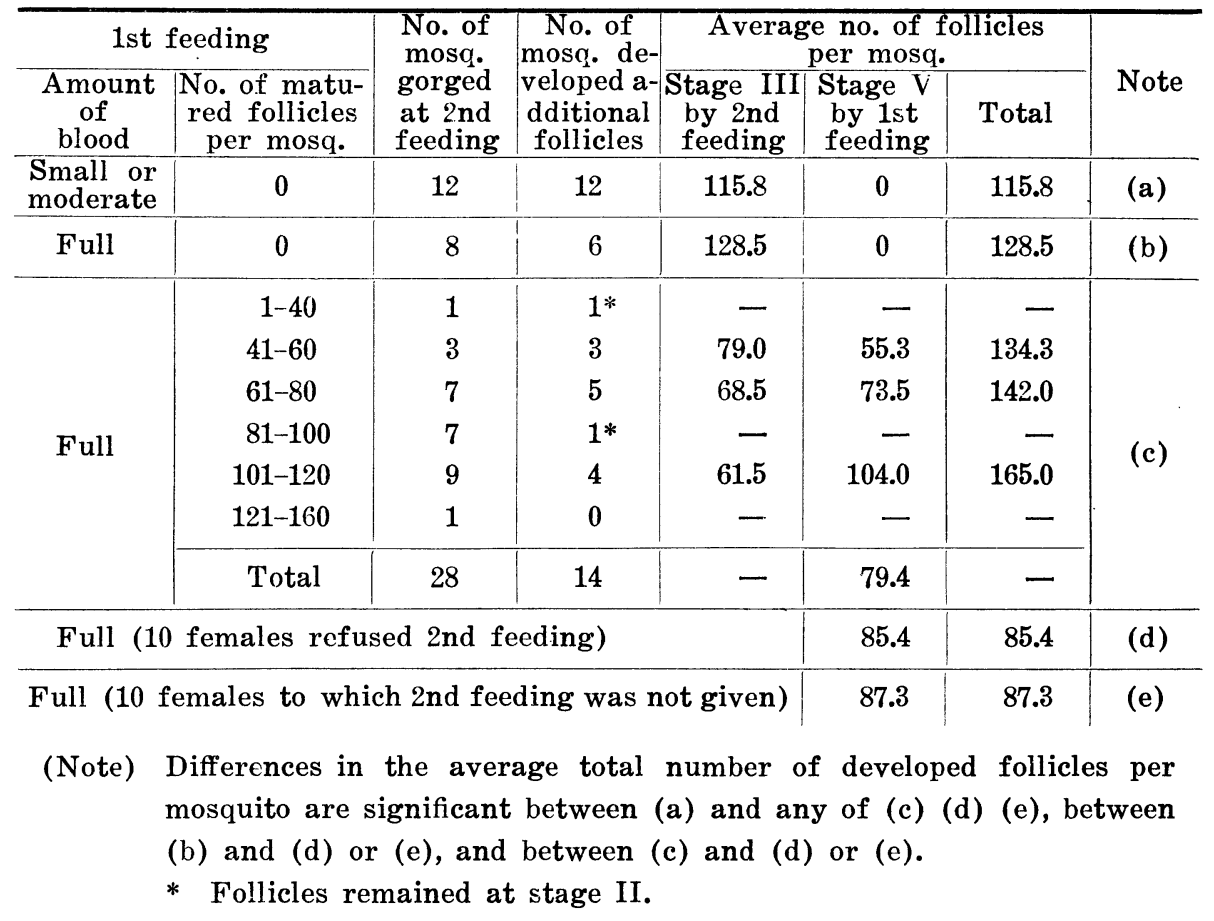

upper three rows of c) after the first feeding than among those which had formed a larger number of eggs (the lower three rows of $c$ ). The average number of follicles per mosquito caused to develop by the second feeding was also greater among the former groups. The differences might be due to differences in the number of remaining potentially active follicles, since the amount of ingested blood in mosquitoes of any group, whether gravid or not, were sufficiently great to permit the growth of a considerable number of follicles. It may be a matter of course that the greatest amount of follicle growth took place in those mosquitoes which developed follicles following both of the two feeding. Even apparently fruitless blood feeding, however, seems to have imposed some stimulating effect on the first-stage follicles, because mosquitoes which exhibited gonotrophic dissociation after a first feeding developed a larger number of follicles after a second feeding than they were expected to be able to do as the result of a single effective feeding ( $a$ and $b$ compared with $d$ and $e$ in Table 7 ).

\section{Follicle Growth in Mosquitoes fed on Artificial Meals}

Up to the present time there has been no record of oviposition without a blood meal among such species of the mosquito as showing the habit of blood- 
sucking, except that a few species belonging to Aedes, Theobaldia and Culex are able or accustomed to do so (Bates, 1949). As far as the writer is aware, C. pipiens of the typical form is to require blood or, at least, blood fractions for egg production. Although Huff (1929) records egg laying in this mosquito on various diets including vegetable juices, the author might possibly have dealt with an autogenous species; since it is described also that a female laid viable eggs without having taken food of any kind. Working with $C$. pipiens pallens the present writer found that, among various foods other than blood tentatively offered, both casein and hen's egg proved efficacious by themselves in developing follicles of this mosquito to a greater or less extent, and that extracts of chicken's tissues also could provide some supplementary nourishments.

(1) Casein

Mosquitoes with a wing length of $4.05 \mathrm{~mm}$ on an average were fed on dilute sugar water for 2-6 days before they were subjected to the experiment. These were given a $5 \%$ solution of casein containing $2 \%$ glucose. (Casein was first dissolved in $0.1 \mathrm{~N} \mathrm{NaHCO}_{3}$ to $10 \%$ and the resultant solution was diluted with an equal volume of Ringer's solution containing $4 \%$ glucose.) Controls were fed on Ringer's solution (containing $2 \%$ glucose) alone.

Altogether 37 females were dissected following such feeding on casein fluid, out of which 4 females showed follicles developed to some extent; whereas all the ovaries in the controls remained at the first stage. Details of the follicle growth are shown in Table 8, which indicate that, although a considerable number

Table 8. Follicle growth in casein-fed mosquitoes

\begin{tabular}{|c|c|c|c|c|}
\hline \multirow{2}{*}{$\begin{array}{l}\text { Days after } \\
\text { feeding }\end{array}$} & \multirow{2}{*}{ Ovaries } & \multirow{2}{*}{ Follicle stage } & \multicolumn{2}{|c|}{ No. of follicles } \\
\hline & & & In each ovary & Total \\
\hline 3 & $\begin{array}{l}\text { Both sides } \\
\text { together }\end{array}$ & II & - & 242 \\
\hline 7 & $\left\{\begin{array}{l}\text { One side } \\
\text { Other side }\end{array}\right.$ & $\begin{array}{l}\text { II } \\
\text { II }\end{array}$ & $\begin{array}{r}102 \\
87\end{array}$ & 189 \\
\hline 7 & $\left\{\begin{array}{l}\text { One side } \\
\text { Other side }\end{array}\right.$ & $\left\{\begin{array}{l}\text { III } \\
\text { III } \\
\text { IV }\end{array}\right.$ & $\begin{array}{l}8 \\
4 \\
2\end{array}$ & 14 \\
\hline 7 & $\left\{\begin{array}{l}\text { One side } \\
\text { Other side }\end{array}\right.$ & $\left\{\begin{array}{l}\text { II* } \\
\text { III } \\
\text { II* } \\
\text { IV }\end{array}\right.$ & $\begin{array}{rr}\text { ca } 50 \\
3 \\
\text { ca } 50 \\
3\end{array}$ & $\begin{array}{l}\text { ca } 100 \text { (II)* } \\
6 \text { (III, IV) }\end{array}$ \\
\hline
\end{tabular}

* Degenerating follicles

of follicles attain the second stage on the casein meal, the rate of growth in. them is retarded and the majority of the growing follicles exhibit a tendency to degenerate. Moreover, a few follicles in the advanced stages were extraordinarily small in size $(400-450 \mu$ at stage IV). It is of interest that the casein-fed mosquitoes, if they did not develop follicles to the second stage, 
were furnished with a larger number of stage-I follicles than those fed on Ringer's solution alone; i. e. the follicles amounted to $320 \pm 15$ on an average in the former group and $259 \pm 30$ in the latter.

In another experiment, mosquitoes were given a meal of either casein fluid or Ringer's solution, followed by daily feeding tests on human blood. It was found that the number of blood-fed females was smaller in the casein-fed lot than in the control, while the opposite relation was observed with respect to the mortality. Concerning the number of follicles matured subsequently to the blood meal, the difference between the casein-fed lot and the control was insignificant.

(2) Hen's egg

A similar but more favorable effect on the follicle growth was demonstrated with hen's egg. The yolk and white of hen's egg were emulsified, usually together with a quater their volume of either Ringer's solution or distilled water for obtaining an appropriate viscosity and also with some glucose to facilitate the feeding. The more dilute the fluid, the more readily it was imbibed by the mosquitoes. The results are summarized in Table 9. As is

Table 9. Follicle growth in mosquitoes fed

\begin{tabular}{cccccc}
\multicolumn{5}{c}{} & \multicolumn{5}{c}{ on emulsion of hen's egg } \\
\hline $\begin{array}{c}\text { Dilution } \\
\text { of food }\end{array}$ & $\begin{array}{c}\text { Days } \\
\text { after } \\
\text { feeding }\end{array}$ & $\begin{array}{c}\text { No. of } \\
\text { mosq. } \\
\text { dissected }\end{array}$ & $\begin{array}{c}\text { No. of } \\
\text { gravid } \\
\text { mosq. }\end{array}$ & $\begin{array}{c}\text { Follicle } \\
\text { stage }\end{array}$ & $\begin{array}{c}\text { No. of } \\
\text { follicles } \\
\text { developed }\end{array}$ \\
\hline $4 / 5$ & 6 & 2 & 0 & & \\
$4 / 5$ & 3 & 5 & 4 & III & $81-165$ \\
$1 / 5$ & 2 & 6 & 0 & & \\
$1 / 2$ & 2 & 7 & 1 & II & numerous \\
$4 / 5$ & 1 & 11 & 4 & II & numerous \\
$4 / 5$ & 2 & 2 & 1 & II & numerous \\
$4 / 5$ & 3 & 5 & 2 & II & numerous \\
$4 / 5$ & 7 & 17 & 2 & V & $63-125$ \\
\hline \multicolumn{7}{r}{ Total } & & 71 & 14 & &
\end{tabular}

evident, the number of follicles developing beyond stage II in these mosquitoes are far greater than those obtained after casein feeding, in some instances equaling the level of egg formation following an engorgement of human blood. The number of gravid mosquitoes, nevertheless, was not so great, for unknown reasons. As a rule, the ingested meal entered the oesophageal diverticula at first, being removed to the stomach within a day, and remained there for a considerable period without a rapid decrease in volume.

(3) Extracts of chicken's tissues

Further experiments were undertaken in order to see whether there are some tissues other than blood efficacious in egg production of the mosquitoes. Several organs were dissected out from a cock or a hen, and emulsified together 
with 2-4 times the volume of Ringer's or Tyrode's solution in a homogenizer at freezing temperature. The following materials served for the feeding.

(A) Original samples

1) Citrated whole blood: slightly diluted compared with untreated whole blood.

2) Blood corpuscles: suspended in a salt solution keeping the volume ratio equal to that of whole blood.

3) Blood plasma: obtained from citrated blood.

4) Brain, 5) muscle, 6) liver, 7) spleen, 8) kindney, 9a) testis and 9b) ovary: emulisified together with 2-4 times its volume of salt solution.

10) Salt solution: Ringer's or Tyrode's solution alone for control.

Table 10. Number of mosquitoes developed follicles following feeding on various tissue extracts of chickens

\begin{tabular}{l|c|c|c|c}
\hline \multirow{2}{*}{ Source of food } & \multicolumn{2}{|c|}{ Original sample } & \multicolumn{2}{c}{ Diluted sample } \\
\cline { 2 - 5 } & $\begin{array}{c}\text { No. of mosq. } \\
\text { dissected }\end{array}$ & $\begin{array}{c}\text { No. of gravid } \\
\text { mosq. }\end{array}$ & $\begin{array}{c}\text { No. of mosq. } \\
\text { dissected }\end{array}$ & $\begin{array}{c}\text { No. of gravid } \\
\text { mosq. }\end{array}$ \\
\hline Whole blood & 23 & 7 & 25 & 5 \\
Blood corpuscles & 19 & 4 & 23 & 2 \\
Plasma & 31 & 0 & 31 & 0 \\
Brain & 25 & 0 & 27 & 0 \\
Muscle & 29 & 0 & 25 & 0 \\
Liver & 31 & 0 & 31 & 1 \\
Spleen & 27 & 0 & 31 & 1 \\
Kindney & 23 & 0 & 31 & 0 \\
Testis & 14 & 0 & 13 & 3 \\
Ovary & 17 & 0 & 15 & 2 \\
Control & 34 & 0 & 27 & 0
\end{tabular}

Table 11. Details of follicle growth in the gravid mosquitoes listed in Table 10

\begin{tabular}{lcccc}
\hline Source of food & $\begin{array}{c}\text { Days after } \\
\text { feeding }\end{array}$ & $\begin{array}{c}\text { No of } \\
\text { mosq. }\end{array}$ & $\begin{array}{c}\text { Follicle } \\
\text { stage }\end{array}$ & $\begin{array}{c}\text { No. of } \\
\text { follicles }\end{array}$ \\
\hline Whole blood & 3 & 3 & II & $112-167$ \\
Do. & 6 & 4 & V & $43-195$ \\
Do. (with casein) & 3 & 4 & II & $89-322$ \\
Do. (with casein) & 3 & 1 & III & 83 \\
Blood corpuscles & 3 & 3 & II & $125-221$ \\
Do. (with casein) & 6 & 1 & V & 228 \\
Do. (with & 3 & 2 & III & $72-73$ \\
Liver (with casein) & 5 & 1 & II & numerous \\
Spleen (with casein) & 5 & 1 & II & 278 \\
Testis (with casein) & 3 & 2 & II & numerous \\
Do. (with hen's egg) & 6 & 1 & V & 116 \\
Ovary (with casein) & 5 & 1 & III & 7 \\
Do. (with casein) & 5 & 1 & IV & 72 \\
& & & &
\end{tabular}


(B) The above samples diluted with $5 \%$ casein fluid or emulsion of hen's $\mathrm{egg}$ to $1 / 5$ of the original concentration. Between 12 and 20 females were employed in the test of each sample. Fed mosquitoes were dissected as usual, giving the results summarized in Table 10 and 11.

Growth of follicles occurred in those mosquitoes which had fed on citrated whole blood or blood corpuscles (both being either diluted or not) as well as on emulsions of the liver, spleen, testis and ovary (all the latter four being diluted with casein fluid or emulsion of hen's egg). There is a reason in that the original samples of the emulsions of the above organs failed to induce egg formation. Since fragments of the tissues have proved liable to settle out of suspension, they must not have been fine enough for the mosquitoes to suck in, in a sufficient amount. Consequently the insects, having imbibed only the water-soluble fractions, would fail to obtain a sufficient amount of the protein factors indispensable to the growth of the follicles. This deficiency would be naturally filled by supplementing the original samples with casein or hen's egg. Although both of the latter two may be capable of developing follicles by themselves, the effect is considered unimportant so far as the present lots of mosquitoes are concerned, since the majority of the insects, including all the controls, have exhibited no signs of follicle development.

\section{Discussion}

There may be at least several factors which form integral parts of the egg production in $C$. pipiens pallens. They are enumerated as follows: 1) number of ovarioles produced in the ovaries of an adult female, 2) physiological state of the ovarian follicles, 3) kind and amount of the ingested food, and 4) physiological conditions in the digestion of the food.

Among these, factors 1), 2) and 4) seem to be determined mainly by the breeding conditions, although gradual changes may also occur during the course of imaginal life. Some experiments performed in relation to this problem will be reported later (Part IV and V). Presumably the above factors may be responsible for the great variation in egg production, which was observed among various lots of the mosquitoes fed equally on human blood to repletion. By grouping these mosquitoes according to their wing length, it was found that, concerning the number of developed eggs, the majority of the insects were included within the ranges of normal distributions, whereas the others contained no or an extremely small number of eggs. Among the latter group of the egg production, mosquitoes which showed gonotrophic dissociation were predominant. It is of interest that $C$. pipiens pallens females reveal strong inclination to either producing a large number of eggs or, otherwise, to complete sterility. The intermediate unstable conditions of the ovary are eliminated mostly by degeneration of some of the stage-II follicles. 
As was first suggested by Nicholson (1921), the degeneration of follicles may be due to shortage of nutriments, and the constituents of degenerating follicles may be utilized by other follicles. The slow rate of follicle maturation after feeding of the mosquitoes on an insufficient amount of food or on a food poor in nourishment can be explained by this reasoning. No inhibitory influences of follicles in later stages upon those in earlier stages are recognizable, since ingestion of an additional blood meal enables an additional number of small follicles to mature, irrespective of the presence of large follicles.

Nutritional requirements of the ovarian follicles do not seem much different among various species of mosquitoes, and the human blood furnishes the mosquitoes invariably with the least adequate nourishment among various sources of the blood (Roy, 1931; Roubaud and Mezger, 1934; Tate and Vincent, 1936; Work, 1937a, c). The same conclusion is arrived at with $C$. pipiens pallens and C. tritaeniorhynchus. As to the effect of blood components on egg production, more or less discordant results obtained by various authors (Tate and Vincent, 1936; Woke, 1937b; Yoeli and Mer, 1938) may be due to differences of experimental conditions. C. pipiens pallens did not develop follicles on citrated hen's plasma, though they did so on blood corpuscles. In a recent experiment with sufficiently active females, however, egg formation took place in several individuals of the same subspecies fed on citrated hen's plasma. The result will be reported elsewhere, but the case was rather exceptional compared with feeding on the blood corpuscles.

According to Roy (1936), A. aegypti lays on eggs after feeding on an amount of blood below a definite minimum weight, over which the number of laid eggs increases with the amount of ingested blood. A similar result is obtained in the follicle development of C. pipiens pallens. Roy considers that the minimum amount of blood is required for stimulation of follicles and any excess is utilized as nourishment. This stimulatory effect may be compared with the initial development of follicles reported by Mer (1936), which can be induced with various foods other than blood; i. e., sugar, fruit juice, milk, pepton, haemoglobin, etc. (Nath, 1924; Christophers et al., 1936; Mer, 1936; Yoeli and Mer, 1938); or without any food in the case of autogenous species. A first blood meal is usually followed by both the entire process of development of the primary follicles and the initial development of the secondary follicles (Nicholson, 1921; Christophers et al., 1936). When the mosquitoes are less active, the first blood meal may fail to induce maturation of eggs; nevertheless it promotes the initial development of the follicles, thus favoring egg production following the second gorging (Mer, 1936). According to Yoeli and Mer (1938), erythrocytes are responsible for the entire development of the follicles, whereas serum is only capable of causing development of second-stage follicles up to maturity. These authors are of the opinion that factors required for develop- 
ment of follicles beyond the second stage are present both in the stroma of erythrocytes and in serum.

In $C$. pipiens pallens the initial development of follicles involves the entire course of the first stage but hardly any of the second stage. About the end of the first stage, the follicles enter the resting period, usually resuming further development only after blood feeding by the mosquito. The second stage may correspond to the beginning of the germinal vesicle stage of the oocyte nucleus, as is described by Nath (1924) with $C$. fatigans, and is considered as the most critical period for the follicles, because in this stage the metabolic activity of the oocyte and the murse cells seems to increase exceedingly. It is natural, therefore, that the degeneration of follicles takes place mostly in the second stage.

What kind of nutritional factors, then, will limit the development of follicles? Casein is capable of causing the development of the ovaries up to the second stage, which cannot be attained by the ovaries of $C$. pipiens pallens after feeding on sugar or fruit. The fact that a small percentage of follicles in some individuals has developed beyond the second stage on a casein meal, may be explained by thinking that this is achieved at the expense of degenerating follicles. As is indicated by Lichtenstein (1948), casein seems to satisfy the protein requirement of the follicles almost completely. It follows that the difficulty of later development of the ovaries on a casein meal must presumably be due to a shortage of some factors other than such common proteins.

There is more evidence to support this concept. Degeneration of growing follicles regularly occurs shortly after feeding on human blood, when the ingested blood is still remaining in a considerable volume and the oocytes have accumulated only a small amount of yolk. The ovaries can develop normally on a solution of casein, provided this is supplemented with a small amount of tissue extracts of chicken testis or ovary. The experimental results may indicate that some constituents of blood, especially of blood corpuscles, are responsible for the later-stage development of the ovaries, and that these factors are also contained in chicken's testes, ovaries and eggs. Such factors may be reserved in the mosquito body in a small amount, which enables the oocytes to accumulate some yolk after taking a casein meal. Presumably these factors may also be responsible for the differences of efficacy in egg production among various sources of blood.

\section{SUMMARY}

1. Number of follicles developing or matured in the mosquito after one full feeding on human blood varies extensively even among individuals with equal wing length. There is found, however, a simple functional relationship between wing lengths and the means of these numbers.

2. When the mosquitoes are fed on human blood, degeneration occurs in a large number of follicles at the second stage of development. The ratio of 
these degenerating follicles is kept fairly constant among the mosquitoes with equal wing length, irrespective of the differences in the actual number of follicles produced or starting development in each individual.

3. Both the number of mature follicles and the rate of follicle development varies considerably, depending on the amount or kind of ingested blood. The results are not different from those obtained by previous workers with various species of mosquitoes.

4. Gonotrophic dissociation occurred not uncommonly among the mosquitoes fed on human blood in the laboratory. These mosquitoes, however, almost invariably matured eggs following the second meal, in a number larger than that which would be expected from the result of a single blood feeding.

5. Feeding on a $5 \%$ solution of casein promoted growth of the first-stage follicles, which developed to the second stage in some individuals; nevertheless only a small proportion of these follicles were able to develop beyond this stage. Mosquitoes fed on hen's egg could develop a considerable number of follicles up to the final stage.

6. Blood corpuscles of chickens proved efficacious in promoting egg formation of the mosquitoes. Among various organs of chickens, the testis and the ovary were found to contain some growth factors, which could be utilized by the mosquitoes as supplements to casein in raising a large number of follicles to maturity.

\section{REFERENCES}

(1) Bates, M.: The natural history of mosquitoes. New York, Mac Millan Co., 1949.

(2) Christophers, S. R., Sinton, J. A. and Covell, G.: How to do a malaria survey. Delhi, Hlth Bull., no. 14, 1936.

(3) Hosoi, T.: Influence of temperatures on the development of Culex pipiens var. pallens (a preliminary note). Shanghai Sizenkagaku Kenkyusho Iho., 14, 339, 1944 (in Japanese).

(4) Hosoi, T.: Egg production in Culex pipiens pallens Coquillett. 1. Seasonal changes., Jap. J. Med. Sci. Biol., 7, 1, 1954

(5) Huff, C. G.: Ovulation requirements of Culex pipiens Linn. Biol. Bull., 56, $347,1929$.

(6) Imms, A. D.: On the larval and pupal stages of Anopheles maculipennis, Meigen. J. Hyg., 7, 291, and Parasit., 1, 103, 1907-8.

(7) Lichtenstein, E. P.: Growth of Culex molestus under sterile conditions. Nature, 162, 999, 1948.

(8) Mer, G. G.: Experimental study on the development of the ovary in Anopheles elutus, Edw. (Dipt. Culic.). Bull. Ent. Res., 27, 351, 1936.

(9) Nath, V.: Egg-follicles of Culex. Quart. J. Micr. Sci., 69, 151, 1924.

(10) Nicholson, A. J.: The development of the ovary and ovarian egg of a mosquito, Anopheles maculipennis, Meig. Quart. J. Micr. Sci., 65, 395, 1921.

(11) Roubaud, E. et Mezger, J.: Influence du sang d'oiseau sur la fécondité du mostique commun, Culex pipiens L. Bull. Soc. Path. exot., 27, 666, 1934. 
(12) Roy, D. N.: On the ovulation of A. stephensi. Ind. J. Med. Res., 19, 629, 1931.

(13) Roy. D. N.: On the rôle of blood in ovulation in Aëdes aegypti Linn. Bull. Ent. Res., 27, 423, 1936.

(14) Tate, P. and Vincent, M.: The biology of autogenous and anautogenous race of Culex pipiens L. (Diptera: Culicidae). Parasit., 28, 115, 1936.

(15) Woke, P. A.: Comparative effects of the blood of man and of canary on egg-production of Culex pipiens Linn. J. Parasit., 23, 311, 1937a.

(16) Woke, P. A.: Effects of various blood fractions on egg production of Aëdes aegypti Linn. Am. J. Hyg., 25, 372, $1937 \mathrm{~b}$.

(17) Woke, P. A.: Comparative effects of the blood of different species of vertebrates on egg-production of Aëdes aegypti Linn. Am. J. Trop. Med., 17, $729,1937 \mathrm{c}$.

(18) Yoeli, M. and Mer, G. G.: The relation of blood feeds to the maturation of ova in Anopheles elutus. Trans. Roy. Soc. Trop. Med. Hyg., 31, 437, 1938. 